Original Research Article

\title{
Sonographic features of neonatal intestinal malrotation and volvulus
}

\author{
Dinakar $\mathbf{P}^{1}$, Bhart Reddy $\mathrm{D}^{2}$, Mithila $\mathbf{M}^{3}$, Deepika $\mathrm{D}^{4}$ \\ ${ }^{1}$ Dr Dinakar Prithviraj, Associate Professor, ${ }^{2}$ Dr. Bharath Reddy, Assistant Professor, ${ }^{3}$ Dr. Mithila Das Mazumder, Junior \\ Resident, ${ }^{4}$ Dr. Deepika Dodda, Junior Resident, all authors are affiliated with Department of Pediatrics, Vydehi Institute \\ of Medical Sciences and Research Institute, Bengaluru, Karnataka, India.
}

Address of Correspondence: Dr Dinakara Prithviraj, Associate Professor, Department of Pediatrics, Vydehi Institute of Medical Sciences, Bangalore. E-mail: drdinakar.nishanth@gmail.com

\begin{abstract}
Background: Normally third portion of duodenum is always retromesenteric-retroperitoneal. Demonstration of intramesentric position of D3 on ultrasound can help in diagnosis of malrotation. Objective: The aim of this study was to evaluate the feasibility of Ultrasound in demonstrating the retroperitoneal D3 for early and effective diagnosis of malrotation. Methods: A 5-year prospective observational study was done between April 2011 to March 2016 in the neonatal ICU of Vydehi institute of medical sciences. 122 neonates presented with features of vomiting and abdominal distension. After ruling out all medical and surgical causes (other) possibility of malrotation was suspected in 41 babies were included in the study. Plain abdominal radiography, sonography and upper gasto intestinal barium examinations were performed in all the 41 suspected cases. Results: All the 41 cases were evaluated and later surgical intervention was done. 26 out of 41 cases had ultrasonographic features of malrotation, which were subsequently proved by surgery. Inversions of Superior mesenteric artery and Superior mesenteric vein were found in all the 26 cases that were surgically proved of malrotation. Other features like thickened duodenal wall greater than $2 \mathrm{~mm}$ in 16 cases, intraperitoneal location of third part of duodenum in 13 cases, distal dilatation of the SMV in 11 cases, duodenal dilatation with tapering configuration in 10 cases and ascites in 14 cases were found. Conclusion: Ultrasonography provides good diagnostic results in neonatal intestinal malrotation. Specific Sonographic features relating to volvulus should be evaluated as potential indicators of the need for an emergent operation.
\end{abstract}

Keywords: Radiograph, Ultrasound, Doppler study, Malrotation

\section{Introduction}

Malrotation is an abnormal fixation of the bowel within the peritoneal cavity and usually involves the small and less likely large bowel. Malrotation is associated with abnormal bowel fixation by mesenteric bands leading to increased risks of bowel obstruction, volvulus and bowel necrosis [1]. The malrotation can be an omphalocele in newborns to an asymptomatic nonrotation of the large and small bowel in adults. Any delay in the diagnosis of malrotation may lead to bowel necrosis, short bowel syndrome and the dependence on total parenteral nutrition. Seventy-five percent of symptomatic cases are diagnosed during neonatal period and up to $90 \%$ of cases become symptomatic during the first year of life [2]. Malrotation occurs in approximately 1 in 500 births. Malrotation is usually

Manuscript received: $10^{\text {th }}$ February 2017

Reviewed: $16^{\text {th }}$ February 2017

Author Corrected: $22^{\text {nd }}$ February 2017

Accepted for Publication: $28^{\text {th }}$ February 2017 diagnosed in newborns and young infants; up to $75 \%$ of symptomatic cases occur in newborns, and up to $90 \%$ of symptomatic cases occur within the 1st year of life [3]. The classic clinical manifestation of malrotation in newborns is bilious vomiting with or without abdominal distention associated with either duodenal obstructive bands or midgut volvulus. A delay in diagnosis and treatment may result in small-bowel necrosis, short- gut syndrome, and dependence on total parenteral nutrition. Mortality in affected newborns was approximately 30\% in the $1950 \mathrm{~s}$ and $1960 \mathrm{~s}$ but since then has markedly decreased, to $3 \%-5 \%$ [4].

Among the various diagnostic methods for malrotation, Conventional radiographs are neither sensitive nor specific for malrotation. UGI series indicate an abnormal position of the duodeno jejunal junction, usually to the right of the midline. Barium enema may 
also show an abnormal position of the cecum [5]. However, the results of radiological studies are not always conclusive. The study is difficult to perform in neonates as it needs an optimal gastric barium filling, a direct fluoroscopic visualization of the contrast agent movement, multiple projection radiographs, manipulation, and, in doubtful cases, delayed images or repeated exams. The false positive and false negative results of UGI series has been reported up to 15-30\% and $6 \%$, respectively. Furthermore, some studies have shown deficiency of UGI series in ruling out the malrotations [6].

Ultrasound is a widely available, noninvasive and inexpensive diagnostic tool that has been used for the diagnosis of malrotation in some studies. If the ultrasound could be used to diagnose or exclude malrotation with acceptable precision, it would allow this serious abnormality to be diagnosed quickly without the need for further costly and difficult studies.

The aim of this study was to assess the feasibility of Ultrasonography for early and accurate is the diagnosis of malrotation and to associated complications like volvulus so as to avoid undue delay decreasing the mortality and morbidity.

\section{Materials and Methods}

A 5-year prospective observational study was done between April 2011 to March 2016 in the neonatal ICU of Vydehi institute of medical sciences. A total of 1950 neonates were admitted during this period of which ultrasound abdomen was done in 1060 babies for various reasons. 122 neonates presented with features of vomiting and abdominal distension. After ruling out all medical and surgical causes (other than malrotation) possibility of malrotation was suspected in 41 babies were included in the study. Plain abdominal radiography, sonography and UGI barium examinations were performed in all the 41 suspected cases.

The double bubble appearance with sparse distal air was used as a characteristic finding on plain radiograph for the diagnosis of malrotation. UGI barium examination showing abnormal configuration of duodenal $\mathrm{C}$ loop for the diagnosis of malrotation. In ultrasonography of abdomen characteristic features of position of third part of duodenum (D3)-retroperitoneal or not, uncinate process of pancreas-in midline and does not cross D3 on axial view on ultrasound, Renal vein-coursing between the SMA and aorta to drain into inferior venacava and relation of SMA and SMV, SMA and SMV anterior to aorta, Distal SMV dilatation, Whirlpool sign, Duodenal dilatation with distal tapering and duodenal wall edema $>2 \mathrm{~mm}$ were looked into to for diagnosing malrotation and later confirmed by surgery.

Plain abdominal radiography, sonography, and UGI barium examinations were performed immediately when the patients had symptoms suggestive of malrotation. The results of sonographic studies, radiologic examinations, and operative findings of the patients were correlated and reviewed.

The sonographic study was performed by a sonologist using curvilinear probes Hd1 1 XE -Philips, Mainly used was C8-5, Cardiac probe 12-14, Linear probe, L 12-3.

All of the patients were examined in the supine posture, Because air may decrease the sensitivity of the sonographic demonstration of the duodenum and other areas of the bowel.

The anteroposterior diameter of the proximal SMV (the segment of the SMV above the umbilical area) and the distal SMV (the segment of the SMV below the umbilical area) were measured.

The distal SMV was considered dilated if its diameter was greater than that of the proximal SMV. In addition to diagnosing malrotation by ultra- sonography, we also evaluated specific sonographic and color Doppler features that can be used to predict the presence of volvulus. The sonographic and barium studies were correlated with the operative findings.

Color Doppler ultrasonographic features were used to confirm the SMA with arterial flow and SMV with venous flow and to detect the presence of whirlpool sign. The CDUS criterion for whirlpool sign showed the SMV winding around the SMA. Color gain was adjusted dynamically during examination to maximize the visualization of blood flow. Precautions were taken to avoid misinterpretation of vascular images caused by color noise and motion artifacts induced by patient movements.

Statistical analysis: To compare the mean values of variables two populations were used: Mann-Whitneytest and ANOVA. The correlation of two numerical characteristics was examined using Spearman's and Pearson's correlation coefficient. The suitability of numeric variables was tested using ROC (receiver operating characteristic) curves. 


\section{Results}

Of the 121 cases with features of abdominal distention and vomiting, only 41 of cases were suspected of malrotation. All the 41 cases were evaluated and later surgical intervention was done. 26 out of 41 cases had ultrasonographic features of malrotation, which were subsequently proved by surgery. Out of 26,11 were complicated with volvulus with malrotation and 3 had meconium ileus with malrotationof the 26 cases 17 were male and reamining 9 were female babies. All the cases had vomiting, around $85 \%$ had abdominal distention.Around $82 \%$ presented within first 15 days of life with average age of presentation was $12+/-6$ days.

Table-1: Sonographic, Radiographic, and Surgical Correlation in 41 Newborn Infants with Suspected Malrotation

\begin{tabular}{|c|c|c|}
\hline Diagnosis of malrotation( $(n=41)$ & $\begin{array}{l}\text { Surgically Diagnosis of Proved } \\
\text { Cases of malrotation }(n=26)\end{array}$ & Negative cases $(n=15)$ \\
\hline Sonographic diagnosis $(n=26)$ & 26 & 0 \\
\hline $\begin{array}{l}\text { Plain abdominal radiographs } \\
\text { A)Double bubble sign With sparse distal air } \\
\qquad(\mathrm{n}=15)\end{array}$ & 9 & 6 \\
\hline $\begin{array}{l}\text { B)Double bubble sign Without distal air } \\
\qquad(\mathrm{n}=11)\end{array}$ & 5 & 6 \\
\hline c)Non specific findings/no findings $(\mathrm{n}=15)$ & 2 & 13 \\
\hline $\begin{array}{l}\text { UGI barium diagnosis } \\
\text { A)Positive findings }(n=20) \\
\text { B) Negative findings }(n=21)\end{array}$ & $\begin{array}{c}18 \\
8\end{array}$ & $\begin{array}{c}2 \\
13\end{array}$ \\
\hline
\end{tabular}

Table 1 shows all the 26 surgical proven cases of malrotation had one or more ultrasonographic features of malrotation with $100 \%$ positive predictive value for ultrasonography with colour doppler study

Table-2: Ultrasonography Features of Malrotation in 26 Newborn Infants.

\begin{tabular}{|c|c|c|c|}
\hline \multirow[t]{2}{*}{ Sonographic and Number of CDUS Features Patients } & \multicolumn{2}{|c|}{ Surgically proven cases $(n=26)$} & \multirow[t]{2}{*}{ P value } \\
\hline & positive & Negative & \\
\hline $\begin{array}{c}\text { D3 position-intraperitoneal } \\
\text { Positive } \\
\text { Negative } \\
\end{array}$ & $\begin{array}{c}18 \\
8 \\
\end{array}$ & $\begin{array}{l}0 \\
0\end{array}$ & 0.011 \\
\hline $\begin{array}{c}\text { Position of the SMA and the SMV relative to each other } \\
\text { Positive } \\
\text { Negative }\end{array}$ & $\begin{array}{c}26 \\
0\end{array}$ & $\begin{array}{l}0 \\
0\end{array}$ & 0.001 \\
\hline $\begin{array}{c}\text { Relation to (D3)- uncinate process of the pancreas } \\
\text { Positive } \\
\text { Negative }\end{array}$ & $\begin{array}{c}13 \\
9\end{array}$ & $\begin{array}{l}2 \\
2\end{array}$ & 0.017 \\
\hline $\begin{array}{c}\text { Distal SMV dilatation } \\
\text { Positive } \\
\text { Negative }\end{array}$ & $\begin{array}{c}10 \\
9\end{array}$ & $\begin{array}{l}3 \\
4\end{array}$ & 0.018 \\
\hline $\begin{array}{c}\text { Whirlpool sign } \\
\text { Positive } \\
\text { Negative }\end{array}$ & $\begin{array}{l}6 \\
8\end{array}$ & $\begin{array}{c}0 \\
12\end{array}$ & 0.222 \\
\hline $\begin{array}{c}\text { Duodenal wall thickness more than } 2 \mathrm{~mm} \\
\text { Positive } \\
\text { Negative }\end{array}$ & $\begin{array}{c}14 \\
6\end{array}$ & $\begin{array}{l}4 \\
2\end{array}$ & 0.012 \\
\hline $\begin{array}{c}\text { Duodenal dilatation with distal tapering } \\
\text { Positive } \\
\text { Negative } \\
\end{array}$ & $\begin{array}{c}10 \\
8 \\
\end{array}$ & $\begin{array}{l}4 \\
4\end{array}$ & 0.032 \\
\hline $\begin{array}{c}\text { Ascites } \\
\text { Positive } \\
\text { Negative }\end{array}$ & $\begin{array}{c}16 \\
4\end{array}$ & $\begin{array}{l}2 \\
4\end{array}$ & 0.014 \\
\hline
\end{tabular}


Table 2 shows that about 11 out of 26 (42\%) showed plain radiographic features of malrotation whereas 18 out of 26 (69\%) had UGI barrium studies showing positive correlation with surgical diagnosis of malrotation. If $\mathrm{P}$ value $<0.001$ is considered significant. Inversions of SMA and SMV were found in all the 26 cases that were surgically proved of malrotation. Other features like thickened duodenal wall greater than $2 \mathrm{~mm}$ in 16 cases, intraperitoneal location of third part of duodenum in 13 cases, distal dilatation of the SMV in 11 cases, duodenal dilatation with tapering configuration in 10 cases, and ascites in 14 cases. Color Doppler ultrasonographic features like whirlpool sign was seen in 7 cases, where all were complicated with volvulus. There is significant ultrasonographic feature like intraperitoneal position of duodenum, relationship of SMV and SMA, relationship of uncinate process with duodenum, distal dilatation of SMV and ascites in predicting in the malrotation. The stastical analysis was done by chi square test.

Table-3: Analysis of Sonographic Features and surgical correlation: malrotation with Volvulus in Children.

\begin{tabular}{|c|c|c|c|c|}
\hline & Sensitivity (\%) & Specificity (\%) & PPV (\%) & NPV (\%) \\
\hline Distal SMV dilatation & 84 & 89 & 86 & 14 \\
\hline Whirlpool sign & 88 & 94 & 100 & 0 \\
\hline Duodenal wall thickness more than 2mm & 82 & 87 & 82 & 76 \\
\hline Duodenal dilatation with distal tapering & 64 & 76 & 66 & 83 \\
\hline Ascites & 83 & 88 & 87 & 23 \\
\hline
\end{tabular}

Duodenal dilation with distal tapering, Distal SMV dilatation, bowel wall edema, ascites and whirlpool sign were sensitive and specific for detecting volvulus, and had a high positive predictive value for volvulus. Whirlpool showed $100 \%$ positive predictive value, $86 \%$ sensitivity, and $83 \%$ specificity for detecting the presence of volvulus. The sensitivity, specificity, and positive predictive value of duodenal wall thickness greater than $2 \mathrm{~mm}$ were $66 \%, 75 \%$, and $66 \%$, respectively. Presence of ascites showed only $33 \%$ sensitivity and $60 \%$ positive predictive value, but $82 \%$ specificity.

\section{Discussion}

Ultrasound is a widely available, noninvasive and inexpensive diagnostic tool that has been used for the diagnosis of malrotation in some studies. If the ultrasound could be used to diagnose or exclude malrotation with acceptable precision, it would allow this serious abnormality to be diagnosed quickly without the need for further costly and difficult studies. The position of duodenum, especially its third segment (D3), and its adjacent structures should be considered while evaluating malrotation [7]. The D3 is located retroperitoneally between the superior mesenteric artery (SMA), anteriorly and the aorta, posteriorly. In malrotations, the D3 is always intramesenteric and located anterior to the mesenteric vessels. An US study, in contrast to UGI series, may demonstrate retromesenteric and retroperitoneal position of D3 and therefore rule out malrotation [8].

Other features in malrotation shows Superior mesenteric artery (SMA) and superior mesenteric vein (SMV) relationship may be reversed, as normally SMV is right side to that of SMA. Other features in malrotation like, SMV may occupy a position directly anterior or to the left of the SMA, SMV and SMA lies anterior to aorta third part of duodenum posterior to SMA and anterior to Aorta. The echogenicity of uncinate process of pancreas lies lateral to third part of duodenum and does not cross the midline. In Doppler ultrasonographic study for malrotation features like Distal SMV dilation and Whirlpool sign can be seen [9].

Two technical points should be kept in mind when evaluating the SMA/SMV relationship. First, scan as caudally as possible; at the portal confluence, the SMV occupies the most ventrally vertical position with respect to the SMA and may erroneously suggest malrotation. Second, place the transducer over the midline and not over the liver; rightward deviation will falsely move the SMV to the left and possibly ventral to or left of the SMA. In individuals with malrotation, the mesenteric attachment of the midgut, particularly the portion from the duodenojejunal junction to the cecum, is abnormally short. The gut is therefore prone to twist counterclockwise around the superior mesenteric artery and vein. This condition, known as midgut volvulus, may cause intermittent abdominal distention and pain or acute bowel necrosis [10].

In malrotation, the D3 is always intraperitoneal and anterior to the mesenteric vessels. Diagnosing Malrotation early is an important for the clinicians to 
prevent untoward complications like volvulus and bowel wall necrosis causing significant mortality and morbidity. It's a diagnostic challenge as plain radiographs and UGI barium studies are non-specific, whereas ultrasonography plays a vital role in diagnosing at a very early stage avoiding complications. The patients with malrotation have had a failure of counterclockwise rotation of the SMV around the SMA, which should have occurred during normal embryologic bowel development in Nichols and li. An abnormal position of the SMA and SMV has been demonstrated to be reliable in the diagnosis of intestinal malrotation. Our results confirm this observation and show that the inversion of the SMA and SMV was $100 \%$ sensitive in detecting neonatal intestinal malrotation.

Barium UGI studies had been unable to accurately predict which patients with malrotation are at risk for midgut volvulus. The abnormal position of the duodenum and SMA, with a whorl- like pattern around the SMA, was suggestive of volvulus. Our study confirms previous reports that the whirlpool sign (SMV winding around the SMA) demonstrated sonographically is sensitive in detecting volvulus. We also found that duodenal dilation with distal tapering configuration, duodenal edema, fixed midline bowel, and dilation of the SMV was other significant predictors of volvulus with high sensitivity and specificity. Water instillation appeared to be helpful in visualizing the superior mesenteric vessels, the level of bowel obstruction, duodenal configuration, and fixed midline bowel (malrotated bowel). With the aid of water instillation into the stomach and duodenum, these additional sonographic features of malrotation could be demonstrated more clearly.

\section{Conclusion}

Ultrasonography provides good diagnostic results in neonatal intestinal malrotation. Specific sonographic features relating to volvulus should be evaluated as potential indicators of the need for an emergent operation.

Funding: Nil, Conflict of interest: None initiated, Perission from IRB: Yes

\section{References}

1. Yousefzadeh DK, Kang L, Tessicini L. Assessment of retromesenteric position of the third portion of the duodenum: an US feasibility study in 33 newborns. Pediatr Radiol. 2010 Sep;40(9):1476-84. doi: 10.1007/ s00247-010-1709-4. Epub 2010 Jun 16.

2. Simpson AJ, Leonidas JC, Krasna IH, et at: Roentgen diagnosis of midgut malrotation: Value of upper gastrointestinal radiographic study. J Pediatr Surg.1972 Jul; 243(7):154-9.

3. Ford EG, Senac MO Jr, Srikanth MS, Weitzman JJ. Malrotation of the intestine in children. Ann Surg. 1992 Feb; 215(2):172-8.

4. Loyer E, Dunne Eggli K.Sonographic evaluation of superior mesenteric vascular relationship in malrotation. Pediatr Radiol.1989 Mar;19(3):173-5

5. R Yanez, L Spitz.Intestinal malrotation presenting outside the neonatal period.Archives of disease in childhood.1986 Jul;71(7):682-685.

6. Long FR, Kramer SS, Markowitz RI .Intestinal malrotation in children: tutorial on radiographic diagnosis in difficult cases. Radiology. 1996 Mar; 198 (3) : 775-80. Doi:101148/radiology.198.3.8628870.

7. Mori H, Hayashi K, Futagawa S, Uetani M, Yanagi $\mathrm{T}$, Kurosaki N. Vascular compromise in chronic volvulus with midgut malrotation. Pediatr Radiol. 1987; 17 (4):277-81

8. Weinberger E, Winters WD, Liddell RM, Rosenbaum DM, Krauter D. Sonographic diagnosis of intestinal malrotation in infants: importance of the relative positions of the superior mesenteric vein and artery. AJR Am J Roentgenol. 1992 Oct;159(4):825-8.

9. Patino MO, Munden MM. Utility of the sonographic whirlpool sign in diagnosing midgut volvulus in patients with atypical clinical presentations. J Ultrasound Med. 2004 Mar;23(3):397-401.

10. Berdon WE. The diagnosis of malrotation and volvulus in the older child and adult: a trap for radiologists. Pediatr Radiol. 1995;25(2):101-3.

\section{How to cite this article?}

Dinakar P, Bhart Reddy D, Mithila M, Deepika D. Sonographic features of neonatal intestinal malrotation and volvulus. J PediatrRes.2017;4(02):133-137.doi:10.17511/ijpr.2017.i02.08. 